\author{
Military Technical College \\ Kobry El-Kobbah, \\ Cairo, Egypt.
}

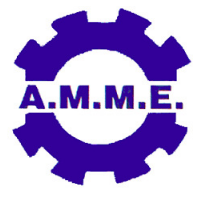

\title{
NEW HORIZONS FOR THE EGYPTIAN METALCASTING INDUSTRY: A VISION BASED ON TECHNOLOGIES DEVELOPED AT CMRDI
}

\author{
A. A. Nofel ${ }^{\star}$
}

\begin{abstract}
The metal casting industry is the cornerstone of industrial development. The demand for metal components is expected to change as new markets and products emerge and others disappear. The Egyptian metal casting industry will need to anticipate emerging industry and consumer needs and provide innovative products that are superior in quality, competitively priced and still with high added-value. New processes will be needed to cast metal components that meet the demanding material specifications and designing of new products. Learning how to meet the technical demands of new products and markets will be essential to the future viability of the metal casting industry itself.
\end{abstract}

The Egyptian imports of casting reached alarmingly high figures, meanwhile the idle capacity of this industry in 2012 exceeded 200,000 ton. The main reasons include: lack of investments in new technologies and initiatives for new casting products, and hence as inadequate quality levels of local production.

Since its establishment in the early 1970's, the Metal Casting Group of CMRDI has been instrumentally engaged with R. \& D. programs together with the Egyptian foundry industry, aiming at introduction of new technologies and developing of new casting alloys to the Egyptian market, as well as development of human resources working in that field. This report highlights those efforts and explains how they can serve as outlines for a rod-map for the development of metal casting industry over the coming years; to fill the gap between production and demand.

Examples are:

- Introduction of ductile iron technology and the subsequent production of castings of vital importance such as spare parts for textile machinery and rolls for steel rolling mills.

- Production technology of the revolutionary material; the austempered ductile iron (ADI) and exploring its potential applications in automotive, agricultural, earthmoving and transmission parts.

- Optimization of abrasion resistance/toughness properties combination of griding media alloys used in cement and mineral processing industries.

* Foundry Technology Department, Central Metallurgical R. \& D. Institute (CMRDI). Email: Adelnofel@hotmail.com. 
- Production of strategic casting with applications in deface industries.

- Introduction of investment casting and its implementation in medical implants and turbine-blades production.

- Another technology under development that should be tackled soon is the prediction of iron melt quality before casting of large castings used in Wind Turbines, which will represent an essential input to the Egyptian Wind Energy development program.

The potential implementation of the above-mentioned technologies for the production of high-added value castings to the existing foundries or for the establishment of new production facilities will be discussed as a base for a road-up of the metal casting industry.

The possible role of the experimental foundry at CMRDI in development of human resources and provision of continuous training programs for foundry personnel on different levels will be elaborated. Moreover, higher specialized courses on technological and metallurgical aspects of the metal casting industry will be suggested, based on more than 40-years experience in R. \& D. interaction with the metal casting industry in Egypt and abroad. 